\title{
Cell Edge Features Affected by Microtubule Inhibitor Combinations
} Sonal Uppal*, Nancy Boudreau**, Elizabeth Wendt*, and Carol Heckman*

\author{
* Center for Microscopy \& Microanalysis, Bowling Green State University, Bowling Green, OH \\ ** Department of Applied Statistics and Operations Research, Bowling Green State University, \\ Bowling Green, $\mathrm{OH} 43403$
}

The tumor promoter, phorbol 12-myristate 13-acetate (PMA), enhances tumor yield through an epigenetic mechanism. PMA, like another promoter, phosphatase inhibitor okadaic acid, works by maintaining proteins in a phosphorylated state. In order to identify chemicals with promoter and antipromoter effects, this laboratory has developed a standard curve of morphogenetic changes using data from precancerous cell lines that eventually became neoplastic. Using the curve as a basis of comparison, we defined the "signature" phenotype as that adopted when a cell line became neoplastic. The results of solving for signature type disclosed that the microtubule-depolymerizing compound, colchicine, had a promoter-like effect [2]. The opposite effect was found if cells were exposed to paclitaxel (Taxol®) and colchicine [3]. Such findings gave clinicians a rationale to test microtubule inhibitor combinations [4]. Therapy is only effective when agents are administered nearly simultaneously. In the current work, we study the effect of inhibitor combinations on cell features defined by computer-assisted microscopy and classification methods based on latent factors.

When administered to cells, paclitaxel or cephalomannine alone enhanced factor \#7, a descriptor of protrusions dependent upon p21-associated kinase [5]. The agents left factor \#4, representing filopodia or microspikes, unaffected. Paclitaxel administered along with various microtubuledepolymerizing compounds elevated factor \#7. 1:1 combinations of paclitaxel with colchicine, nocoazole, or vinblastine, all had the same effect. A 3:1 molar ratio of paclitaxel to podophyllotoxin or vinblastine was similar. Thus, protrusions were commonly enhanced by taxanes alone or in combination with depolymerizing agent. The prevalence of filopodia, determined by comparing factor \#4 values with control, was only affected by an equimolar combination of paclitaxel and colchicine or 3:1 molar ratio of paclitaxel to podophyllotoxin. This endpoint was unaffected by taxane exposure but did respond to a high concentration of the paclitaxel analog, 7-deoxytaxol. Morphological correlates of the two types of cell features were sought by immunofluorescence localization of microtubules in cells fixed with $-20^{\circ}$ methanol. Control cells exhibited numerous microtubules arranged parallel to the cell edge (Fig. 1a). Only where cells made contact did microtubules typically appear to be perpendicular to the cell edge. In contrast, after $2 \mathrm{~h}$ exposure to the combination of paclitaxel with colchicine, microtubules were rearranged so that a part of the array extended straight out from the peripheral cytoplasm (Fig. 1b). This effect was observed after exposure to paclitaxel with podophyllotoxin and vinblastine (Fig. 2) as well. From these studies, it can be concluded that both the features represented by \#4 and \#7 can be influenced by taxanes and for \#4, particularly by the combination of paclitaxel with microtubule-depolymerizing agents.

\section{References}

[1] Work supported in part by DOD grant DAMD17-01-1-0484

[2] C. A. Heckman et al., J. Cell. Physiol. 166 (1996) 217.

[3] C. A. Heckman et al., Int. J. Oncol. 16 (2000) 700.

[4] V. Dieras et al., Anti-Cancer Drugs 7 Suppl. 2 (1996) 47.

[5] C. A. Heckman et al., Exp. Cell Res. 295 (2004) 432. 

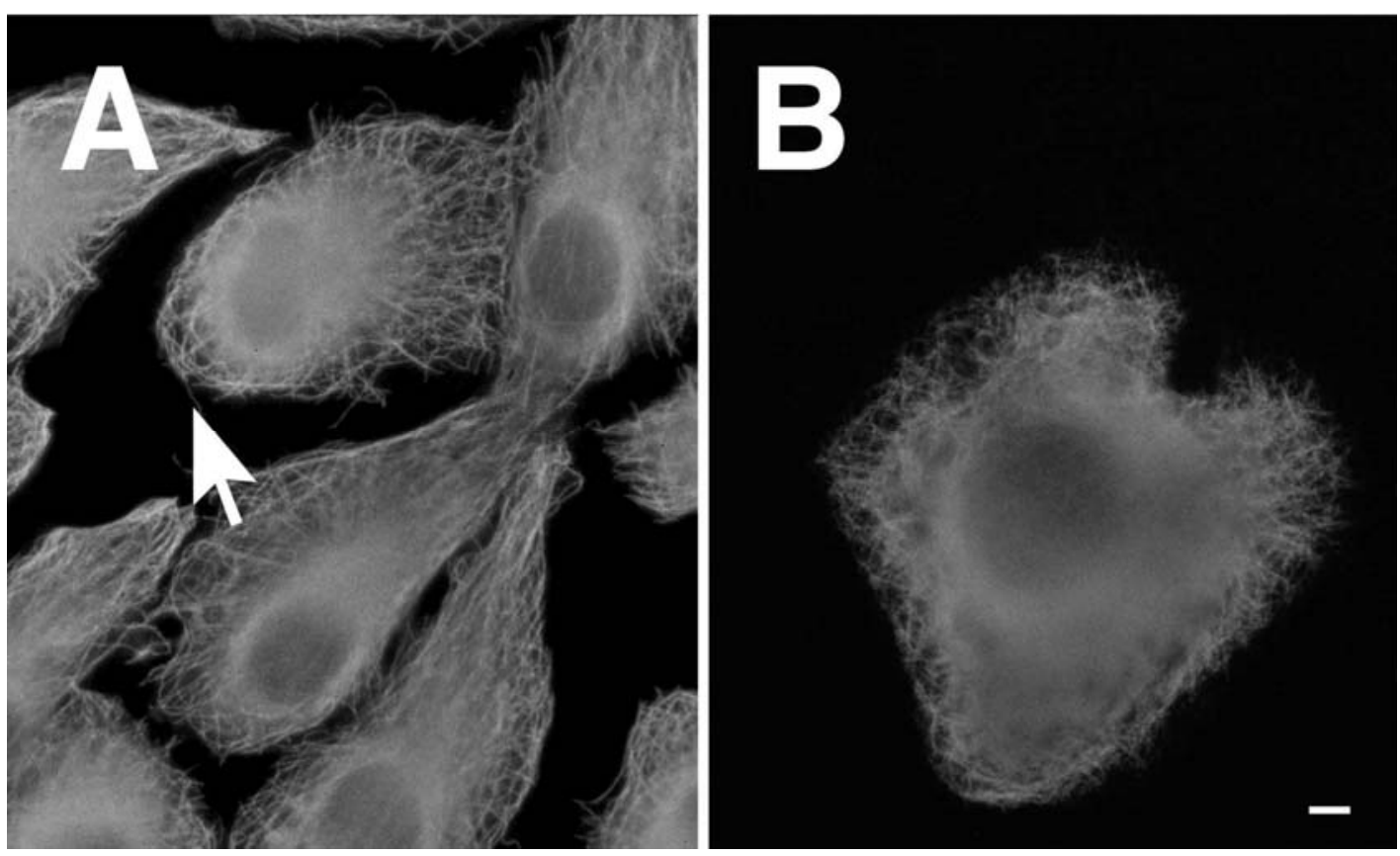

Fig. 1. Comparison of IAR20 PC1 cells showing the arrangement of microtubules. Cells were stained with mouse antibody against beta-tubulin, followed by FITC-labelled anti-mouse antibody. A) Control with vehicle only. At the cell boundary (arrow), microtubules are arranged parallel to the edge. B) Cells treated with combination of microtubule inhibitors $2 \mu \mathrm{M}$ paclitaxel and $2 \mu \mathrm{M}$ colchicine. Bar $=10 \mu \mathrm{m}$.
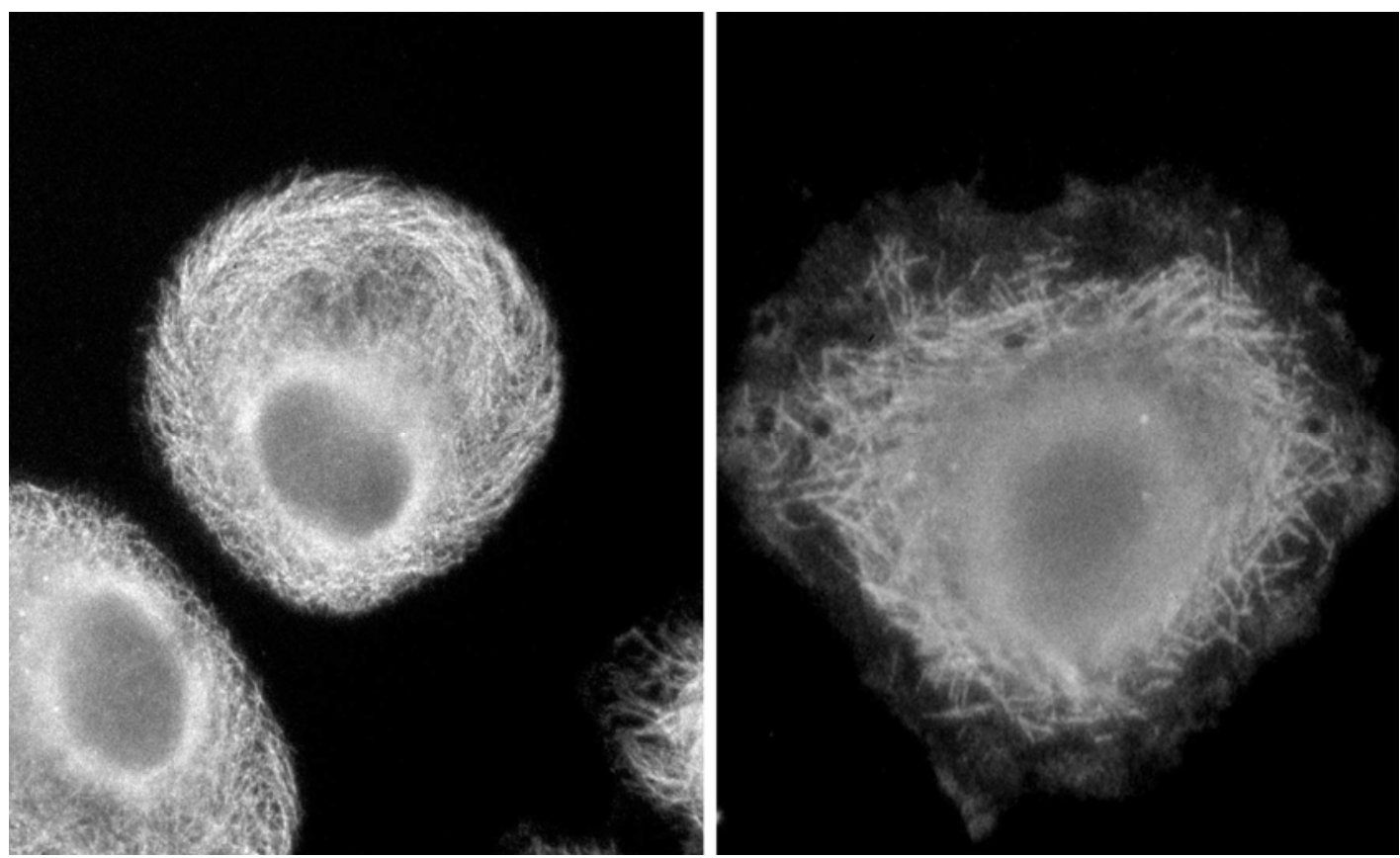

Fig. 2. Comparison of IAR20 PC1 cells treated with a combination of microtubule inhibitors. (Left) Cells treated with $6 \mu \mathrm{M}$ paclitaxel plus $2 \mu \mathrm{M}$ vinblastine. (Right) Cells treated with $6 \mu \mathrm{M}$ paclitaxel plus $2 \mu \mathrm{M}$ podophyllotoxin. Cell edges show microtubules extending perpendicularly onto the substrate. 